saw ber soon after ber admission into the Bombay County Jail in a true epileptic seizure, which was extremely violent and prolonged, laving her bruised and helpless for hours. She was unmigtakably melancholic and weak, but otherwise there was notbing in her history to explain the occurrence of the disease which she suffered from every twelve or fifteen days, and which seemed totally disconnected with menstruation. She was put under a course of the bromide, a liberal diet was allowed, and her functions were attended to. Sonn after commencing the treatment she had a fit in the High Court, whilst under examination (dropping the child she was originally charged with dropping), and becoming violently convulsed. The case was necessarily adjourned, and treatment was persevered with. After a short interval she again attended the court, when the emotion, although just as strong as before, did not induce a fit. I cannot sprak so positively of the favourable action of the bromide in this case, because the charge against the woman fell through, and I lost sight of her.

I am fully aware that many points arise in these cases which admit of controversy. They are not adduced as proving anything; they are simply tentative, and are reported more for the sake of drawing attention to the subject, and inviting discussion, than of clearing up the question of etiolngy or treatment. Still, I think there is enough similarity to justify $m e$ in grouping them togetber, and sufficient, ground for concluding that a strong and absorbing depressing passion may excite, and that bromide of potas. sium will calm, that peculiar irritability of the nervous system of which convulsive movements are the outward manifestation.

Bombay.

\section{THIRTEEN CASES OF LITHOTOMY.}

\section{By G. HEATH, M.B. Lond.}

The accompanying table gives the result of thirteen lithotomies, the whole number performed by me in public and in private practice during the period given in the table. The number is not large, as it is spread over a little more than eighteen months. The whole number recovered, and the majority in less than the usual time. The patients were all males; the ages varied from three to sixty-six years; and the smallest stone weighed $15 \mathrm{grs}$, the largest 354 grs. The greatest number of days of treat- ment was seventy-four, the least eleven; but in this case the wound was not absolutely cicatrised. The patient, however, operated upon in the infirmary, was able to leave that institution and travel to his home-a distance of nine miles. In two cases-Nos. 5 and 9-the median operation was performed; in the others the ordinary lateral operation.

In all a tube was used.

The greater number of the cases do not require any individual notice; it may be interesting to say a few words concerning others.

CASE 5.-This patient was a stout, big man, and had been, for some time before I saw him, under treatment for enlarged prostate and irritable bladder, with purulent urine. On sounding, it was ascertained that there were more stones than one, aud, as these were considered to be small, lithotrity was determined upon. So much constitutional disturbance and irritability of the bladder, with increase of pus in the urine, followed the examination, although very carefully conducted, that the crushing operation was given up, and median lithotomy, which I bad before found useful in the extraction of foreign bodies from the bladder, resorted to. The membranous part of the urethra was opened, the apex of the enlarged prostate only incised; the finger then passed easily into the bladder, coming upon three stones lying tngetber behind the gland. These were picked out in surcesion by somewhat small flatbladed forceps. Each stione was flat, circular, about half an inch in diameter, with a thicken rim round the edge. They were found afterwards to consist of urate of ammonia, and to weigh together $60 \mathrm{grs}$. The recovery was excellent. No urine passed by the wound after forty-eight hours. In a week the patient was out of bed, and soon left home for change of air.

CASE 10.-Lithotomy is not usmally, I think, an operation attended by much bleeding, hut in this case the hæmorrhoidal and transverse perineal arteries bled profusely, so that some eight ounces of blnod were lost during the short time occupied by the operatirn. The bleeding was easily stopped by plugging the petticoat of the tuhe and raising the patient's hips, but $I$ was a little anxious about the result. This patient was a nervons delicate man, a schoolmaster, and had suffered a gond deal from bis complaint for some time. The stone measured $1^{\frac{3}{4}}{ }^{\prime \prime}$ in its long diameter, $1 \frac{1}{4}^{\prime \prime}$ in its short; the greater circumference was $4 \frac{1}{4}^{\prime \prime}$, the less $3 \frac{1 "}{8}$. It was found to be phosphatic. The patient left the infirmary on the eleventh day.

CASE 3 was longer under treatment than any other. The rectum was very large, and formed a pouch projecting anteriorly. This was cut during the operation to the

Tabular Statement of Dr. Heath's Thirteen Cases of Lithotomy.

\begin{tabular}{|c|c|c|c|c|c|c|c|c|}
\hline Case. & Sex. & Age. & Date of Operation. & Date of Result. & $\begin{array}{l}\text { Nature of } \\
\text { Result. }\end{array}$ & $\begin{array}{c}\text { Number } \\
\text { of Stones. }\end{array}$ & $\begin{array}{l}\text { Weight } \\
\text { of Stones. }\end{array}$ & Composition of Stones. \\
\hline 1 & Male & 10 & 17rb May, 1873 & 31st May, 1873 & Cured & 1 & 120 grains & Phosphates \\
\hline 2 & ," & 3 & 17th May, 1873 & 10th June, 1873 &, & 1 & 15 grains & Oxalate of Lime \\
\hline 3 & , & 60 & 19 b July, 1873 & 30th Sept., 1873 & ", & 1 & 120 grains & Oxalate of Lime \\
\hline 4 & , & 9 & 6 th Oet., 1873 & 18 th Oct, 1873 & & 3 & 131 grains & Uric Acid \\
\hline 5 & ", & 69 & 26 b May, 1874 & 9th June, 1874 & , & $\mathbf{3}$ & 60 grains & Urate of A mmonia \\
\hline 6 & , & 8 & 9th July, 1874 & 23rd July, 1874 & & 1 & 160 grains & Urite of Ammonia \\
\hline 7 & ,, & 7 & 18th Aug., $1 \times 74$ & 17th Sept., 1874 & ," & 1 & 50 grains & Oxalate of Lime \\
\hline 8 & , & 16 & 1st Oct., 1874 & 30th Oct., 1874 & 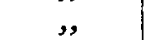 & 1 & 206 grains & Oxalate of Lime \\
\hline 9 & , & 36 & 13 th Oet., 1874 & 27 th Oct., 1874 & و, & 1 & 60 grains & Prosphates \\
\hline 10 & $"$ & 43 & 3rd Nov., 1874 & 13th Nov., 1874 & 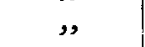 & 1 & 291 grains & Phosphates \\
\hline 11 & , & 60 & 21st Nov., 1874 & 4th Dec., 1874 & "' & 1 & 320 grains & $\begin{array}{l}\text { Uric Acid } \\
\text { Small quantity of Phosphates }\end{array}$ \\
\hline 12 & , & 64 & 22nd Dec., 1874 & 20th Jan., 1875 & " & 1 & 354 grains \{ & $\begin{array}{l}\text { Uric Acid ; Urate of A mmonia: } \\
\text { Phosphates }\end{array}$ \\
\hline 13 & , & 58 & 26th Dec., 1874 & 10th Jan., 1875 & ", & 1 & 160 grains & Phosphates \\
\hline
\end{tabular}

Cases 1, 2, 4, 7, 8, 10 were operated upon in the Neweastle Infirmary.

In Cases $7,8,9,11$, the wound was completely healed. In the other cases the wound was not quite skinned over, but the patients were no Jonger under treatment.

extent of about half an inch, and the healing of the wound delayer in constquence. The after-treatment in this case was ekilfully and carefully conducted by Dr. Callender, of Haydon Bridue.

CAsm 11 presented a very deep perineum, the finger only just reaching the prostatic wound. The stone (uric acid) weighed $320 \mathrm{gr}$., and measured-long diameter, 15"; short diameter, $1 \frac{3 . "}{8}$; great circumference, $4^{\prime \prime}$; less circumference, $3 \frac{1}{2}$. The healing was complete on the fifteenth day.

This case and No. 9 were carefully attended after the operation by Dr. McClarens, of Bedlington, who also assisted me in the operations.

CASE 12.-Here also there was a very deep perineum, and the extraction of the stone was somewhat impeded by its 
peculiar sbape-flattened and circular-measuring $1 \frac{3}{4}$ in each diameter, $37^{\prime \prime}$ in great circumference, and $33^{\circ \prime \prime}$ in less circumference, so that it could not be bumoured in its passage tbrough the wound. This patient suffered from swelled testicle during the third week after the operation, and was twenty-nine days under treatment.

The cases of median operation have given me a favourable impression of that procedure where the stone is of such a size that no dilatation of the neck of the bladder is required; in these cases the least injury possible was inflicted upon the patients, the neck of the bladder being neither cut nor bruised, and they were left in the most favourable position for recovery.

It is very different where the stone is large and cannot be extracted witbont forcible dilatation of the neck. The statistics of the Norwich Hospital show that the median indiscriminately practised gives a higher rate of mortality than the lateral cperation.

In conclusion, I may observe that this table gives a fair sample of the results which I have hitherto been fortunate enough to obtain in my practice of lithotomy, and not in any sense a picked or exceptional series of cases. It confirms, so far as it goes, an opinion which I ventured to give some time agn-tbat lithotomy is one of the operations which is more successful in the present day than it was fifty years ago.

Neweastle-on-Tyne.

\section{9.}

\section{H O P I TAL PRACTICE, BRITISH AND FOREIGN.}

Nnlla autem est alia pro certo noscendi via, nisi quampl urimas et morborum inter se comparare.-MorgagnI De Sed. et Caus. Morb., lib. iv. Proømium,

\section{ST. THOMAS'S HOSPITAL.}

CASE OF SUPPCRATING HYDATID CYST IN THE THIGH; DEATH ; AUTOPSY ; CLINICAL REMARKS.

(Under the care of Mr. Francis Mason.)

For the notes of this interesting case we are indebted to Mr. Reginald Maples, the dresser.

The patient was a strong, healthy-looking man, aged forty-five, who was admitted August 27th, 1874. He stated that he was quite well until two years before admission, when he felt a slight pain in his left femoral region. He remembered that at that time, when he was stooping, he hurt himself with a purse he had in his trowsers pocket, and soon afterwards he noticed a swelling, about the size of a walnut, which increased slowly but steadily. Three months before be sought advice the tumour suddenly got much larger. It never gave him any distinct pain, and his chief anxiety was a swelling of his foot and leg.

On examination, a distinctly fluctuating tumour, about the size of a fortal head, was found situated in the left Scarpa's triangle. The circumference of the thigh at the most prominent part of the swelling was twenty-six inches, while the measurement of the other limb in the corresponding situation was twenty-three inches and a half. The size of the swelling remained unaltered, whether the patient was standing or recumbent. There was no impulse on coughing. He could bear his weight on the affected limb. There was no tenderness in the spinal region, and pressure in the iliac fossa caused no discomfort. There was no aneurismal pulsation or bruit, and moderate manipulation gave but little pain, but rough handling caused a good deal of suffering. The foot and leg were odematous, the codema disappearing only partially after a night's rest in bed. 'The secretions were normal. Appetite good; bowels regular; urine sligbtly acid, with specific gravity 1020

The case having been considered to be either a cyst or a chronic abscess, becoming daily more inflamed, the patient was kept in bed for a few days. On Sept. 2nd a small exploratory puncture was made, when pus only flowed-at first pretty freely, but it soon suddenly ceased. The wound was therefore enlarged, when four pints of purulent fluid loaded with bydatid cysts were evacuated. A poultice was applied, and the patient went on remarkably well for four days, whon he became very feverish, his temperature reaching $1044^{\circ}$.

Sept. 7th.-The discharge, which had been profuse, now almost ceased. The edges of the wound were exceedingly painful, red, and dry. He had an anxious expression of countenance; pulse 112 , and very strong; temperature $103^{\circ}$; bowels constipated. Ordered half an ounce of castor oil.

9th.-Marked improvement generally. Pulse 98 ; temperature $102^{\circ}$; urine loaded with lithates. Ordered bark and ammonia. Profuse discharge, with numerous bydatids, from the wound.

On Sept. 10th he was slightly delirious; and on the 13th he became semi-comatose, refused food, passed bis urine and fæces unconsciously, and, getting gradually weaker, died on the $16 \mathrm{th}$.

The following is the report of the post-mortem examination made by Dr. Turner, the resident assistant-physiciar :Body well nourished; robust frame; much subcutaneous fat, rather yellow. There was a circular wound, about the centre of Scarpa's triangle, on the left side, leading to a cavity running upwards as far as the crural ring, and downwards for about four inches in the course of the muscles, amongst which it burrowed. No œdema of the leg; skin natural. The lungs were congested posteriorly and cdematous; the heart walls were flabby; liver soft and somewhat fatty; spleen soft and dark; kidneys pale.

Remarks. - In commenting on this case Mr. Mason observed that it was so full of interest clinically that before treatment the man was sent to the College of Surgeons during one of the pass examinations. Mr. Mason dwelt especially on the diagnosis of swellings in the femoral region, omitting for the present those met with in the inguinal region. He said that from the proximity of the parts the diseases in this neighbourbood were sometimes grouped together as tumours or swellings in "the groin." He thought it was better, both anatomically and surgically, to describe each region with its diseases separately.

In the case under notice, as there was evident fluctuation, it was clear that the swelling contained fluid of some kind, but there was nothing to indicate the presence of the bydatids until the puncture was made. The man had no tenderness on the spine; he could raise and turn himself in bed without difficulty. There was no impulse on coughing, and no diminution in the swelling when he assumed the recumbent posture. He could also readily extend the thigh on the trunk. These points were a fair proof that the patient was not suffering from psoas abscess, or a reducible femoral hernia. The age of the patient, too, was rather against his having a psoas abscess, such an abscess being more common in children. It might possibly be an iliac abscess, which by opening into the sheath of the psoas might point below instead of, as it usually does, above Poupart's ligament. Mr. Mason directed attention to the difference in the symptoms between a psoas abscess and a femoral hernia, remarking that although there was impulse on coughing in both, and that in both the tumour came suddenly from above downwards, yet that on raising the buttock in psoas abscess the tumour steadily diminished in size, from the fluid running back by gravitation, whereas in femoral hernia, if taxis be employed, the tumour returned quickly and with the characteristic gurgle. Then a femoral hernic was rather unusual in a man, and certainly there were no symptoms of strangulation, such as sickness, constipation, and the dragging colicks pains in the abdomen.

On placing the liub in a particular position there was an arterial thrill, but this thrill was very different from the heaving eccentric pulsation observed in aneurism. Moreover, on making pressure on the external iliac artery the sac could not be in the least emptied as in aneurism. It was clearly not an aneurism.

Again, if it were a solid growth, such as a glandular tumour or simple enlarged lymplatic glands, it would probably be more movable; and if it were a tumour of a malignant character it would be soft and elastic to the touch, rather than distinctly fluctuating, and numerous veins might perhaps be observed ramifying over the skin. Further, if it were a fatty tumour or a piece of omentum, it would have a soft, dougby, irregular feel.

The patient was particularly questioned and examined 